Note

\section{Formation of Green Pigment by Reaction of Quercetin with Cysteine Ethyl Ester}

\author{
Kiharu Igarashi, Yoshio FuruKawa, \\ Hiroshi Arai and Tadahiko YasuI \\ Department of Agricultural Chemistry, \\ Faculty of Agriculture, \\ Yamagata University, \\ Tsuruoka-shi, Yamagata 997, Japan
}

Received May 28, 1982

In the previous paper, we described that quercetin, which is one of the flavonols commonly found in the plant kingdom, gave a browned protein by its nonenzymic reaction with protein, and that the nutritive value of this browned protein was lower than that of unreacted protein. ${ }^{1,2)}$ Subsequently, we have examined the possibility of interaction between quercetin and various amino acids or their derivatives, and amino acid derivatives and various flavonols to clarify the mechanism for the browning reaction of protein with quercetin. We observed that a reaction mixture composed of quercetin and amino acid derivatives developed a green color.

In this study, we investigated the chemical structure of flavonol and amino acid derivatives, and the reaction condition necessary to produce this green color. In addition, the visible absorption spectrum of a green pigment isolated from the reaction mixture was also investigated.

Several reports have described the greening reaction of chlorogenic acid or ethyl caffeate with amino acid. ${ }^{3 \sim 5)}$ But, a study on the greening reaction of quercetin with amino acid derivatives has not yet been reported.

The reaction of quercetin with various amino acids and their derivatives was carried out as follows. To a solution of $0.135 \mathrm{mmol}$ of quercetin in $25 \mathrm{ml}$ of ethanol was added $0.045 \mathrm{mmol}$ of amino acid or its derivative in $50 \mathrm{ml}$ of $1 / 15 \mathrm{M}$ phosphate buffer ( $\mathrm{pH} 6.8$ ). The reaction mixture was refluxed at $80^{\circ} \mathrm{C}$ for $3 \mathrm{hr}$ with air bubbling under a $15 \mathrm{~W}$ fluorescent lamp, the distance between the reaction mixture and the fluorescent lamp being approximately $20 \mathrm{~cm}$. After cooling to room temperature, the reaction mixture was made up to a volume of $100 \mathrm{ml}$ with methanol and the optical densities at 520 and $680 \mathrm{~nm}$ were measured against a deionized water blank in a cuvette with a light path of $1 \mathrm{~cm}$. The effects of exposure of the reaction mixture to the fluorescent lamp and the presence of oxygen in the reaction mixture from formation of the green color with quercetin and an amino acid derivative were examined as follows. Two $\mathrm{ml}$ of ethanol, containing $8.6 \mu \mathrm{mol}$ of quercetin, and $4 \mathrm{ml}$ of $1 / 15 \mathrm{M}$ phosphate buffer ( $\mathrm{pH} 6.8$ ), containing $2.2 \mu \mathrm{mol}$ of $\mathrm{L}$-cysteine ethyl ester hydrochloride were poured into a screw capped test tube, and the reaction mixture held at $80^{\circ} \mathrm{C}$ for $1 \mathrm{hr}$ either under a fluorescent lamp or in darkness. In order to determine the effect of oxygen on the formation of the green color, the oxygen contained in the reaction mixture was first replaced by nitrogen gas and the reaction mixture held at $80^{\circ} \mathrm{C}$ for $1 \mathrm{hr}$ under a fluorescent lamp. One hour after this reaction, the reaction mixture was cooled to room temperature and the optical density at $680 \mathrm{~nm}$ was measured.

In addition, the chemical structure of flavonol necessary to produce the green color was examined. The reaction and measurement were carried out in the same manner described above, except that $8.6 \mu \mathrm{mol}$ of various flavonols were used for the reaction in place of quercetin.

A reaction for the isolation of a green pigment from the reaction mixture was carried out with its volume suitably increased, using as much as $1.35 \mathrm{mmol}$ of quercetin and $0.45 \mathrm{mmol}$ of cysteine ethyl ester hydrochloride, and the reaction mixture was refluxed at $80^{\circ} \mathrm{C}$ for $4 \mathrm{hr}$ with air bubbling under a fluorescent lamp. After this reaction, the reaction mixture was evaporated to remove ethanol and extracted twice with ethyl acetate. The ethyl acetate extract was dehydrated with anhydrous sodium sulfate, filtered and evaporated to dryness. The residue was dissolved in methanol, placed on the top of a silica gel column $(3 \mathrm{~cm} \times 12 \mathrm{~cm})$ and elueted successively with $300 \mathrm{ml}$ of benzene-acetone-formic acid $(18: 8: 1, \mathrm{v} / \mathrm{v})$ solution and $400 \mathrm{ml}$ of $0.1 \%$ hydrochloric acid in methanol. The effluents corresponding to the latter eluent were collected, evaporated to dryness, dissolved in methanol and chromatographed on a cellulose column $(3 \mathrm{~cm} \times 12 \mathrm{~cm})$, using acetic acid-distilled water-hydrochloric acid (30:10:1, $\mathrm{v} / \mathrm{v}$ ). The effluents corresponding to a purple band on the column (the isolated pigment gave a purple color in solution below $\mathrm{pH}$ 4.0) were collected, added to with distilled water, concentrated to a small volume under reduced pressure and centrifuged. The resulting precipitate was suspended in distilled water, re-centrifuged and the precipitate lyophilized. The lyophilized precipitate was dissolved in methanol and chromatographed on a cellulose column $(3 \mathrm{~cm} \times 12 \mathrm{~cm})$ with $88 \%$ formic acid-distilled water-hydrochloric acid $(5: 3: 2, \mathrm{v} / \mathrm{v})$. The effluents corresponding to a purple band on the column were collected and treated as described above to give a lyophilized precipitate. Furthermore, the lyophilized precipitate was dissolved in methanol and chromatographed on a Sephadex LH-20 column $(3 \mathrm{~cm} \times 16 \mathrm{~cm})$ with $0.01 \%$ hydrochloric acid in methanol. The effluents corresponding to a purple band on the column were collected and treated as described above to give a lyophilized precipitate. The precipitate obtained in this way gave a purple color in appearance and only one spot with an $R f$ value of 0.80 by cellulose thin layer chromatography. (Eastman Chromatogram Sheet), using a solvent of acetic aciddistilled water-hydrochloric acid $(30: 10: 3, \mathrm{v} / \mathrm{v})$. In this paper, the isolated precipitate is described in terms of a 


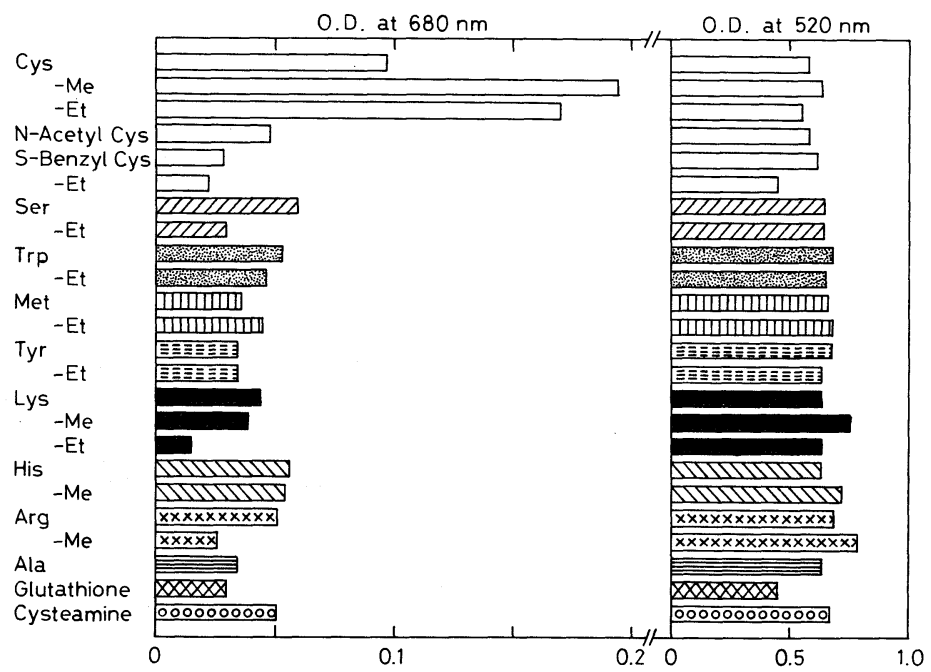

FIG. 1. The Relationship between the Chemical Structure of Amino Acids or Their Derivatives and the Intensity of Green Color in the Reaction Mixture.

The reaction mixture, composed of quercetin and amino acids or their derivatives, was held at $80^{\circ} \mathrm{C}$ under a fluorescent lamp for a fixed time and the green and red color intensities were determined with optical density at 680 and $520 \mathrm{~nm}$, respectively. Me and Et represent the methyl and ethyl esters of each amino acid, respectively.

\section{TABle I. EFFects of Light and Oxygen on the Formation of Green Color}

A reaction mixture composed of quercetin and cysteine ethyl ester was held at $80^{\circ} \mathrm{C}$ under the reaction conditions in Table I for a fixed time, and the formation of green color was examined by measuring the optical density of the reaction mixture at $680 \mathrm{~nm}$.

\begin{tabular}{lc}
\hline \multicolumn{1}{c}{ Conditions } & $\begin{array}{c}\text { O.D. at } \\
680 \mathrm{~nm}\end{array}$ \\
\hline Reacted in the light with oxygen & 0.179 \\
Reacted in the dark with oxygen & 0.017 \\
Reacted in the light with nitrogen & 0.017 \\
\hline
\end{tabular}

green pigment, because it was isolated from the reaction mixture showing a green color and it also gave a green color in a solution of $\mathrm{pH} 6.0$.

The optical densities of the reaction mixtures refluxed for $3 \mathrm{hr}$ are shown in Fig. 1. Only L-cysteine ethyl and methyl esters gave a green color in the course of the reaction with quercetin, while none of the compounds, such as $N$-acetyl-L-cysteine and $S$-benzyl-L-cysteine (which are respectively protected in the $\alpha$-amino and sulfhydryl groups of the moieties), glutathione (which is protected in both the $\alpha$-amino and carboxyl groups in the cysteine residue) and $S$-benzyl-L-cysteine ethyl ester (which has the only free $\alpha$-amino group of the moieties) gave a green color. Therefore, both the $\alpha$-amino and sulfhydryl groups in L-cysteine ethyl or methyl esters seem to be essential to

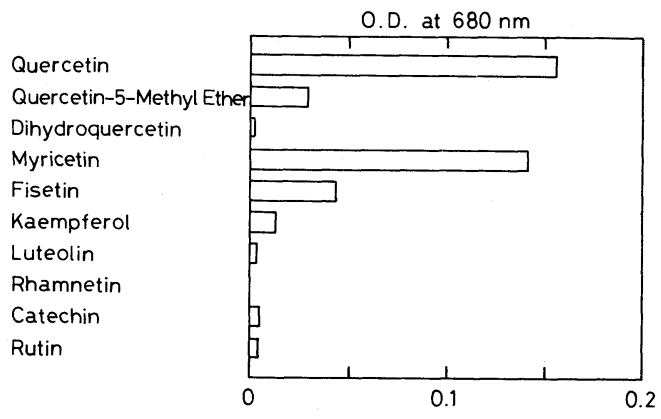

FIG. 2. The Relationship between the Chemical Structure of Flavonol or Its Related Compounds and the Intensity of Green Color in the Reaction Mixture.

The reaction mixture, composed of flavonol or its related compounds and cysteine ethyl ester, was held at $80^{\circ} \mathrm{C}$ under a fluorescent lamp for a fixed time and the intensity of the green color in the reaction mixture was determined with optical density at $680 \mathrm{~nm}$.

form this green color. On the other hand, none of the compounds, such as serine, tryptophane, methionine, tyrosine, lysine, histidine and arginine, together with their ethyl or methyl esters, gave a green color.

The effects of light and oxygen on the formation of the green color are shown in Table I. Development of the green color was observed in the presence of both light and oxygen. This result indicates that both light and oxygen were necessary for formation of the green color by the 


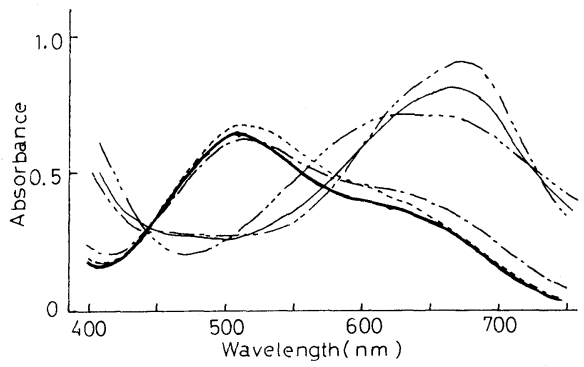

FIG. 3. Visible Absorption Spectra of an Isolated Pigment.

in methanol; ------, in a citrate buffer $(\mathrm{pH} 2.2)-$ methanol solution; ---, in a phosphate buffer ( $\mathrm{pH} \mathrm{4.0)-}$ methanol solution; ----, in a phosphate buffer ( $\mathrm{pH}$ 6.0)methanol solution; __ , in a phosphate buffer ( $\mathrm{pH}$ 6.8)methanol solution; -----, in a phosphate buffer ( $\mathrm{pH} 8.0$ )methanol solution.

reaction of quercetin with L-cysteine ethyl ester.

The relationship between the chemical structure of flavonol or its related compounds and the intensity of the green color of the reaction mixture is shown in Fig. 2. None of the compounds, such as quercetin-5-methyl ether (azaleatin), rutin, dihydroquercetin (which is saturated at the double bond between the 2 and 3 positions of quercetin), fisetin, luteolin and kaempferol gave a green color, while quercetin-7-methyl ether (rhamnetin) gave a yellow precipitate during its reaction with L-cysteine ethyl ester, the yellow color remaining in the supernatant of the reaction mixture. In the case of myricetin, the optical density at $680 \mathrm{~nm}$ was nearly equal to that of quercetin, but an intense reddish color was observed with this reaction. A likely reason for this may be that the ratio of optical density at $520 \mathrm{~nm}$ to that at $680 \mathrm{~nm}$ was very large in myricetin compared with quercetin.

Figure 3 shows the visible absorption maxima of the isolated pigment in solutions of different $\mathrm{pH}$. The pigment showed absorption maxima at $508 \mathrm{~nm}$ in methanol, $668 \mathrm{~nm}$ in a phosphate buffer ( $\mathrm{pH} 6.8)$-methanol, $671 \mathrm{~nm}$ in a phosphate buffer ( $\mathrm{pH} 6.0$ )-methanol, $636 \mathrm{~nm}$ in a phosphate buffer ( $\mathrm{pH} 8.0$ )-methanol, $512 \mathrm{~nm}$ in a citrate buffer ( $\mathrm{pH}$ 2.2)-methanol, and $513 \mathrm{~nm}$ in a phosphate buffer ( $\mathrm{pH}$ 4.0)-methanol solution.

We are now studying the properties and the chemical structure of the green pigment.

\section{REFERENCES}

1) K. Igarashi, N. Shishido and T. Yasui, Nippon Nôgeikagaku Kaishi, 52, 499 (1978).

2) K. Igarashi, T. Ishii, A. Hosoya, K. Yarimizu and T. Yasui, Eiyo to Shokuryo, 33, 35 (1980).

3) H. Horikawa, Tokyo Joshi Ika Daigaku Zasshi, 45, 86 (1978).

4) C. Nakatani and I. Karasawa, Eiyo to Shokuryo, 32, 163 (1979).

5) T. Matsui, J. Nutr. Sci. Vitaminol., 27, 673 (1981). 